\title{
MODERNIZATION OF THE TECHNICAL INFRASTRUCTURE OF THE FUEL AND ENERGY COMPLEX DURING THE TRANSITION TO THE EIGHTH TECHNOLOGICAL ORDER
}

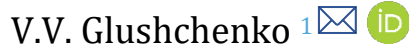 \\ Doctor of Technical Sciences, Associate Professor, Moscow, Russia
}
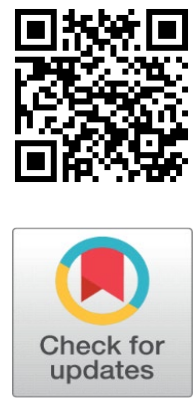

Received 1 September 2021

Accepted 15 September 2021

Published 3 December 2021

\section{CorrespondingAuthor}

V.V. Glushchenko,

valery.v.glushchenko@gmail.com

DOI 10.29121/IJOEST.v5.i6.2021.243

Funding: This research received no specific grant from any funding agency in the public, commercial, or not-for-profit sectors.

Copyright: (C) 2021 The Author(s). This is an open access article distributed under the terms of the Creative Commons Attribution License, which permits unrestricted use, distribution, and reproduction in any medium, provided the original author and source are credited.

OPEN ACCESS

\section{ABSTRACT}

The subject of the work is the methodology of modernization of the technical infrastructure of the fuel and energy complex during the transition to the eighth technological order; the object of the work is the technical infrastructure of the fuel and energy complex during the eighth technological order; the purpose of the work is to reduce the risks of sustainable development of the Russian fuel and energy complex during the formation of the eighth technological order; to achieve this goal, the following tasks are solved: the necessity of modernization of technical infrastructure during the development of a new technological order is justified; the concept and features of the eighth technological order are clarified; the methodology of modernization of technical infrastructure in the process of development of the eighth technological order is formed; the scientific methods of the article are historical, comparative and logical analysis, theory of hierarchical systems, innovation, forecasting, synthesis, expert assessments; the scientific novelty of the article is connected with the substantiation of the methodology of modernization of the technical infrastructure of the fuel and energy complex at its two hierarchical levels, the development of an ecosystem approach in the fuel and energy complex.

Keywords: Machinery, Infrastructure, Modernization, Fuel and Energy Complex, Technological Structure, Sustainable Development, Ecosystem, Machines, Methodology, Risk

\section{INTRODUCTION}

The relevance of the article is determined by the need to modernize the technical infrastructure of the fuel and energy complex in the process of its transition to a new technological order. Such modernization is designed to ensure the sustainable development of the fuel and energy complex. A necessary condition for sustainable development is to maintain the competitiveness of the fuel and energy complex. Modernization will reduce the risk of sustainable development of the fuel and energy complex during the formation of a new technological order. Therefore, the article develops methods of modernization of technical infrastructure in the fuel and energy complex during the transition to the eighth technological order.

The hypothesis of the article is the statement that the development of a methodology for the modernization of technical infrastructure can reduce the risk of sustainable development of the fuel and energy complex during the new technological order. 
The purpose of the work is to reduce the risks of sustainable development of the Russian fuel and energy complex during the formation of the eighth technological order.

To achieve this goal, the following tasks are solved:

- the necessity of modernization of technical infrastructure in the process of development of a new technological order is justified;

- the concept and features of the eighth technological order are clarified;

- concepts of modernization of technical infrastructure are formed in the process of development of the eighth technological order;

- a comparative analysis of the concepts of modernization of the technical infrastructure of the fuel and energy complex is carried out.

The object of the work is the technical infrastructure of the fuel and energy complex under the eighth technological order.

The subject of the work is the development of concepts of modernization of the technical infrastructure of the fuel and energy complex during the transition to the eighth technological order.

Technical infrastructure should be understood as systems of machines designed for their use within the framework of technologies for the functioning of the fuel and energy complex.

Analysis of research topics shows the following. When studying the problems of the fuel and energy complex, it is necessary to use a systematic approach Kislitsyn and Shishkov (2016). The international activity of Russian companies is a factor in stimulating their modernization Karlusov and Yarkov (2020). There is a need to modernize machines at enterprises Yakusheva and Sunteev (2020), Ermolina and Ademasova (2020).When creating a mechanism for the modernization of enterprises, it is recommended to apply a systematic approach Nikonova (2020). The development of a new technological order gives additional urgency to the need to modernize machines Glazyev (2016), Gurieva (2004). The technological order should be considered as a large multilevel system Mesarovich et al. (1973). At the same time, the technical infrastructure of the fuel and energy complex is also a large hierarchical system Mesarovich et al. (1973). Nanotechnology is considered the main factor in the development of a new technological order Glazyev et al. (2009). In the interests of scientific support for the activities of enterprises in the conditions of a new technological order (way), the theory of technological orders was developed Glushchenko (2020). Enterprises should develop strategic plans for their modernization Glushchenko (2021). Such a strategic plan should be based on a certain concept. In the process of developing a new technological way, a number of organizations began to form their ecosystems Borovik and Doroshenko (2020). The head of the Kurchatov Institute proposed to create convergent (nature-like) technologies Kovalchuk (2021). The organizational form of modernization of enterprises during the transition to the eighth technological order will be innovative projects Glushchenko (2020).

It should be expected that during the development of the eighth technological order in the fuel and energy complex, new social and professional institutions (systems of relations) will be formed Glushchenko (2021).

The results of this analysis of the studies already carried out show the following: firstly, the relevance of this article is confirmed; secondly, the need for synthesis of the methodology of modernization of fuel and energy complex machines is justified. 


\section{METHOD}

At the onset of the eighth technological order, modernization of the technical infrastructure of the fuel and energy complex can be carried out as a result of: firstly, separate, random acts of modernization; secondly, within the framework of a certain concept of such modernization. Modernization based on individual acts of innovation activity does not guarantee the sustainability of development and competitiveness of the fuel and energy complex. The conceptual approach to modernization increases the efficiency of the modernization processes of the fuel and energy complex.

Under the concept of modernization of the technical infrastructure of the fuel and energy complex, during the transition to the eighth technological order, we will understand a systematic view of the process and practical results of such modernization.

The period of time from 2021 to 2040 falls on the development of the eighth technological order. It is very logical that during the transition to a new technological order, it is necessary to carry out a purposeful modernization of the fuel and energy complex machines. This is due to the fact that the new technological order is characterized by the rapid development of certain technologies. If the achievements of these technologies are absent in machines, then such machines will be considered obsolete. The lack of modernization may lead to a decrease in the level of competitiveness of the fuel and energy complex. After carrying out a targeted modernization, these machines must correspond to the technological level of the new technological order. It should also be taken into account that these machines are included in the production systems of the fuel and energy complex. In the new technological order, the paradigm of designing production complexes is also changing: the ecosystem approach in such design receives priority development.

This determines the need for a two-level modernization of the production capacities of the fuel and energy complex: firstly, modernization is needed at the level of these machines themselves; secondly, it is necessary to introduce an ecosystem approach at the level of technological systems of the fuel and energy complex.

To develop a methodology for such modernization, it is necessary to know the main features of the new technological order. This complicates the task of modernizing machines for the following reasons: the concept of "technological order" is debatable; there is a discussion on the number of order: six or eight; a list of technologies that are characteristic of this way is being discussed; there is no methodology for modernizing machines; the concept and understanding of the essence of the ecosystem approach has not yet been formed; socio-economic institutions that could provide such modernization and more have not been formed in 2021.

The "institute" is understood as a system of economic, social, industrial, professional relations between their participants.

In 2021, the concept of "technological order" is considered as controversial. For example, the first author considers the technological order as a purely economic system. He believes that the technological order is a system of key international economic institutions Glazyev (2016). However, with this approach, the technological order turns out to be disconnected from the technologies themselves. The second author considers the technological order as a purely technological system: a set of technologies used in the work of the organization Gurieva (2004). 
This approach: firstly, identifies the "technological order" with the "technological basis" of the organization; secondly, this approach does not take into account the need for adequate institutions and other elements of the technological order.

The analysis shows that the technological order (structure) has all the properties of complex hierarchical systems Mesarovich et al. (1973), Glazyev et al. (2009), Glushchenko (2020). Within the framework of the theory of technological orders, it is proposed to understand the technological order as a harmonious union of such parts of it into a single whole: production technologies; professional institutions; forms of management and business; monetary system; world order; forms of scientific and educational activities Glushchenko (2020) Glushchenko (2021).

If we talk about the serial number of the new technological order, then the picture is as follows. The first author believes that this is the sixth technological order Glazyev (2016). However, such numbering of technological structures covers only the period of capitalist development. If we talk about the entire period of historical and technological development, then this is the eighth technological order Glushchenko (2020).

We can talk about such a sequence of technological orders: "1st" technological order. horse traction. time period 2000 BC -9th century AD; "2nd" technological order, Windmill, a water mill, time period 9th century-1770; "3rd" technological order, textile machines, time period 1770-1830; "4th" technological order, steam engine, time period 1830-1880; "5th" technological order, electric motor and internal combustion engine, time period 1880-1930; "6th" technological order, electronic computers, time period 1930-1970; the " 7th " technological order, microelectronics and microprocessors, time period 1970-2010; the " 8th " technological order, nanotechnologies and neurotechnologies, time period 20102040 Glushchenko (2021).

The characteristics of technological structures in the field of the fuel and energy complex are presented in Table 1

\begin{tabular}{|c|c|c|c|c|}
\hline $\begin{array}{c}\text { № } \\
\Pi / \Pi\end{array}$ & $\begin{array}{c}\text { Properties of } \\
\text { technological order in } \\
\text { the fuel and } \\
\text { energy complex / } \\
\text { Number of } \\
\text { technological orders, } \\
\text { time period, name }\end{array}$ & $\begin{array}{c}\text { New types of } \\
\text { fuel }\end{array}$ & energy machines & Energy sources \\
\hline 1. & $\begin{array}{l}\text { The first technological } \\
\text { order, } \\
2000 \text { BC. - } \\
\text { IX century AD; } \\
\text { Horse traction }\end{array}$ & $\begin{array}{c}\text { Animal } \\
\text { excrement, } \\
\text { firewood, coal }\end{array}$ & Horse-drawn traction & $\begin{array}{c}\text { Physical strength } \\
\text { of animals }\end{array}$ \\
\hline 2. & $\begin{array}{c}\text { Second technological } \\
\text { order, } \\
\text { IX century - } \\
1770 ; \\
\text { Windmill, watermill }\end{array}$ & $\begin{array}{c}\text { Animal } \\
\text { excrement, } \\
\text { firewood, coal }\end{array}$ & $\begin{array}{l}\text { Windmills and } \\
\text { watermills }\end{array}$ & $\begin{array}{c}\text { Wind and water } \\
\text { energy }\end{array}$ \\
\hline 3. & $\begin{array}{c}\text { The third technological } \\
\text { order, } \\
\text { 1770-1830; } \\
\text { Textile machines }\end{array}$ & $\begin{array}{c}\text { Animal } \\
\text { excrement, } \\
\text { firewood, coal }\end{array}$ & $\begin{array}{l}\text { Horse-drawn traction, } \\
\text { Windmills and } \\
\text { watermills }\end{array}$ & $\begin{array}{l}\text { Physical strength } \\
\text { of animals, Wind } \\
\text { and water energy }\end{array}$ \\
\hline
\end{tabular}


4.

$$
\begin{gathered}
\text { The fourth } \\
\text { technological } \\
\text { order, } \\
\text { 1830-1880; } \\
\text { Steam engine }
\end{gathered}
$$

Source: developed by the author

The research allows us to conclude that the eighth technological order will be characterized by the development of: a whole complex of new technologies; distributed management systems; matrix organizational structures; ecosystem approach; management of social development of personnel, etc. The results of these studies of the essence and structure of technological structures make it possible to predict trends in the development of the technical infrastructure of the fuel and energy complex for the period up to 2040.

The technical infrastructure of the fuel and energy complex can be considered, at the same time, as an integral part of: the existing technological structure; the developing new technological structure. This determines the need to modernize the technical infrastructure of the fuel and energy complex with the advent of a new technological order.

The eighth technological order is usually called by the name of nanotechnology. It is these technologies that are considered to be the basis of this technological order Glazyev et al. (2009). However, the analysis showed that the technological basis of the new technological order can include: environmentally friendly technologies; nanotechnology; resource-saving technologies; neurotechnologies; digitalization technologies; information technologies Glushchenko (2021).

Under the modernization of fuel and energy complex machines, we will understand the improvement of consumer properties and operational characteristics of these machines by integrating their elements with technologies of a new technological order. 
Therefore, the method of modernization of fuel and energy complex machines should provide for a comprehensive update of the design of such machines through the use of all these types of technologies.

Such a method of modernization of fuel and energy complex machines can be proposed:

- research of the content and results of the introduction of new technologies (for each of the types of new technologies);

- study of the technical and economic characteristics of the existing fuel and energy complex machine and statistics of failures, repairs of this type of machines;

- carrying out an audit of all elements of the existing machine for the possibility of their integration with one of the types of technologies of the new technological order;

- making a technical decision on the possibility of integrating this design element of the machine with one of the types of technologies of the eighth technological order;

- description of the results and changes in the characteristics of the machine after the introduction of a certain type of new technology into it;

- carrying out a technical and economic analysis of the effectiveness of the introduction of this type of technology of a new technological structure into a specific element of the machine;

- making a management decision on the expediency of carrying out the operation of modernization of the machine in question;

- drawing up a project for the modernization of a specific machine by combining all types of modernization of this machine by integrating its elements with a certain type of technology of the eighth technological order;

- development of a complete modernization project of the machine by integrating its elements with all types of technologies of the new technological order.

Let's explain this technique on a hypothetical example of the modernization of a truck carrying out the removal of coal from quarries during open-pit coal mining. At the same time, we note that initially cars belong to the fifth technological order. This technological order covers the time period from 1880 to 1930 . This technological order is named after the name of the electric motor and the internal combustion engine. Serial production of cars began around 1908.

Example No. 1. The methodology for upgrading trucks to work in a coal quarry includes the following stages.

1) It is necessary to divide the car into its constituent elements: metal frame; engine; cab; running system; fuel system; glass cleaning system and more.

2) It is necessary to carry out an audit of the elements of this car to assess the possibility of upgrading these elements of the car by introducing nanotechnology into their production: the metal frame and chassis system of the car can be strengthened using nanotechnology; engine parts can be strengthened through the use of nanotechnology; cabin parts, including the cabin skin can be strengthened using nanotechnology; the fittings of the fuel system can be hardened and protected by an anti-corrosion coating with the use of nanotechnology, at the same time, the characteristics of fuel can be improved; in the cabin glass cleaning system, nanotechnology can increase the strength and wear resistance of metal elements, at the same time, the characteristics of the washing liquid can be improved, and so on; 
3) After that, it is required to conduct an audit of this car to assess the possibility of improving its performance through the use of neurotechnologies. As it is known, neurotechnologies combine three groups of technologies: technologies of the game approach (gamification) in the training of drivers and technical service specialists; technologies of technical registration of the driver's condition during his work; management technologies in emergency situations. The analysis shows what is possible: the use of a game approach in the training of technical personnel and drivers; creation of a device for technical registration of characteristics and monitoring of the driver's condition during operation; based on the integration of neurotechnologies and information technologies, it is possible to create a voice assistant for the driver in dangerous situations of car operation.

4) At the next stage, it is necessary to perform an audit of the car in question in order to study the possibility of using information technology. In the course of such an audit, it may be established that the car is not equipped with a voice assistant for notifying about the critical level of fuel and/or liquid for cleaning the driver's cab glass. The analysis shows that the sudden exhaustion of these liquids (fuel and for cleaning glass) can: create interruptions in the operation of the car (reduces the readiness factor of the car); lead to dangerous situations during operation (the likelihood of material damage and damage to the life and health of the driver). Creation of a driver's voice assistant based on information technology, warning about a small amount of liquid or fuel: it will increase the readiness coefficient of the car; it will reduce the risk of damage, including to the life and health of the driver. The algorithm of operation of such an assistant can be as follows: the liquid level in the tank is monitored (for example, using a float sensor); when the liquid level in the tank drops to a critical level, the device generates an alert signal; this alert signal is transmitted to the sound speakers in the driver's cab; an audio signal is generated notifying the driver of the critical liquid level. This device can be integrated with intelligent technologies. The use of intelligent technologies in such an assistant can make it possible to calculate the critical fluid level taking into account a certain operating scheme of a particular car sample.

Similarly, measures can be developed to modernize such a car using digitalization technologies, resource-saving and environmentally friendly technologies.

5) After completion of the audit of all elements, it is necessary to conduct an expert assessment and analysis of the entire set of modernization measures proposed for all elements of the car. In the course of such an assessment, all modernization measures can be divided, ranked according to the degree of priority of their implementation, and more. For example, the parts that most often fail during operation must be improved first of all, for this, for example, they must be manufactured using nanotechnology to improve their operational characteristics.

The application of the proposed methodology for drafting the modernization of fuel and energy complex machines will allow for a targeted search for opportunities to improve the performance of the car.

The use of such a vehicle modernization technique can significantly increase the effectiveness and economic efficiency of innovation activities.

Similarly, this technique can be applied to other elements of the technical infrastructure of the fuel and energy complex. 
The need to develop a separate method of modernization of machine systems is due to the fact that when combining several different machines into a single system, such a system is created that has new qualities. This property of complex systems is called the property of their emergence. The emergence of a system is the irreducibility of the properties of the entire system to the properties of individual elements of this system Mesarovich et al. (1973).

The analysis shows that new organizational forms of development of the technical infrastructure of the fuel and energy complex in the conditions of the eighth technical order can be called: clusters; technological platforms; ecosystems. In 2021, clusters and technology platforms have already been largely studied. Therefore, the development of the ecosystem approach as a direction of modernization of the technical infrastructure of the fuel and energy complex is an important task of this article.

Considering the concept of "ecosystem", it should be borne in mind that in the management of the system they call what solves the problem. The system consists of a set of elements and links between them. Modernized machines are considered as elements of the ecosystem of the fuel and energy complex. In 2021, the development of ecosystems is also considered as a new paradigm for doing business by companies and the entire fuel and energy complex as a whole. The methodology of the formation of the paradigm of management of the development of a new technological order is reflected in the work Glushchenko (2020). The paradigm of the ecosystem approach is designed to ensure the sustainability of the development of the fuel and energy complex. The structure of the ecosystem approach paradigm can include: philosophy, ideology, policy and organizational culture of such an approach. The philosophy of the ecosystem approach is the most general view of: the place of the fuel and energy complex in the structure of the eighth technological order; the composition and relationships of stakeholders; the mission, goals and objectives of the ecosystem approach, and more.

In the process of modernization of technologies of the fuel and energy complex, the ways of life of all categories of stakeholders of this system should be taken into account. This implies a different psychology of doing business and managing companies, which is based on the habits of various categories of stakeholders (individuals and legal entities). As part of the creation of ecosystems in the fuel and energy complex, we can expect the emergence of processes of integration of technical and humanitarian knowledge. The methodology of creating ecosystems in the fuel and energy complex can be called ecosystem engineering. Such ecosystem engineering is a field of knowledge that harmoniously combines knowledge from various fields of science and practice in order to effectively solve the problems of creating ecosystems, in particular, in the fuel and energy complex.

An ecosystem in the fuel and energy complex is proposed to be called such a technological system that meets the following requirements (principles): comprehensive customer service with a focus not only on meeting their current needs, but also on increasing the duration and comfort of their life cycle; original concept as the basis of business and ensuring business competitiveness; strategic approach; search for an exclusive market niche, the desire to avoid competition based on exclusive ways of providing goods and services; harmonious relations with the external and internal environment of the ecosystem; lean production (minimizing all types of losses); efficient use of all types of resources; taking into account the interests of all parties (stakeholders) interested in the activities of the fuel and energy complex; focus on expanding the boundaries of the fuel and energy resources market; focus on increasing the methods and effects of using fuel and energy resources; increasing the equipment utilization factor; validity and 
regulation of the degree of openness; restoration of land and natural environment in the energy resource extraction zone, and more.

The general directions of ecosystem development in the fuel and energy complex can be considered: an increase in the degree of safety of stakeholders; an increase in the level of comfort of stakeholders' activities; an increase in stakeholder satisfaction.

Tools for creating ecosystems in the fuel and energy complex can be called: a conceptual approach to the creation and modernization of such systems; a programoriented approach; specialization of individual technologies and subsystems; cooperation of technologies and subsystems; competition between technologies and subsystems of one system; maximizing stakeholder loyalty; development of information technologies and mobile applications; multi-channel production activities; digitalization and informatization of production processes; management of social development of personnel and others.

In 2021, the theory of nature-like and ecosystem technologies has not yet been developed. Therefore, it is possible to conduct only a comparative analysis of individual characteristics of such systems and technologies. Comparative analysis of marketing, ecosystem and nature-like (convergent) concepts in the process of modernization of the fuel and energy complex in Table 2.

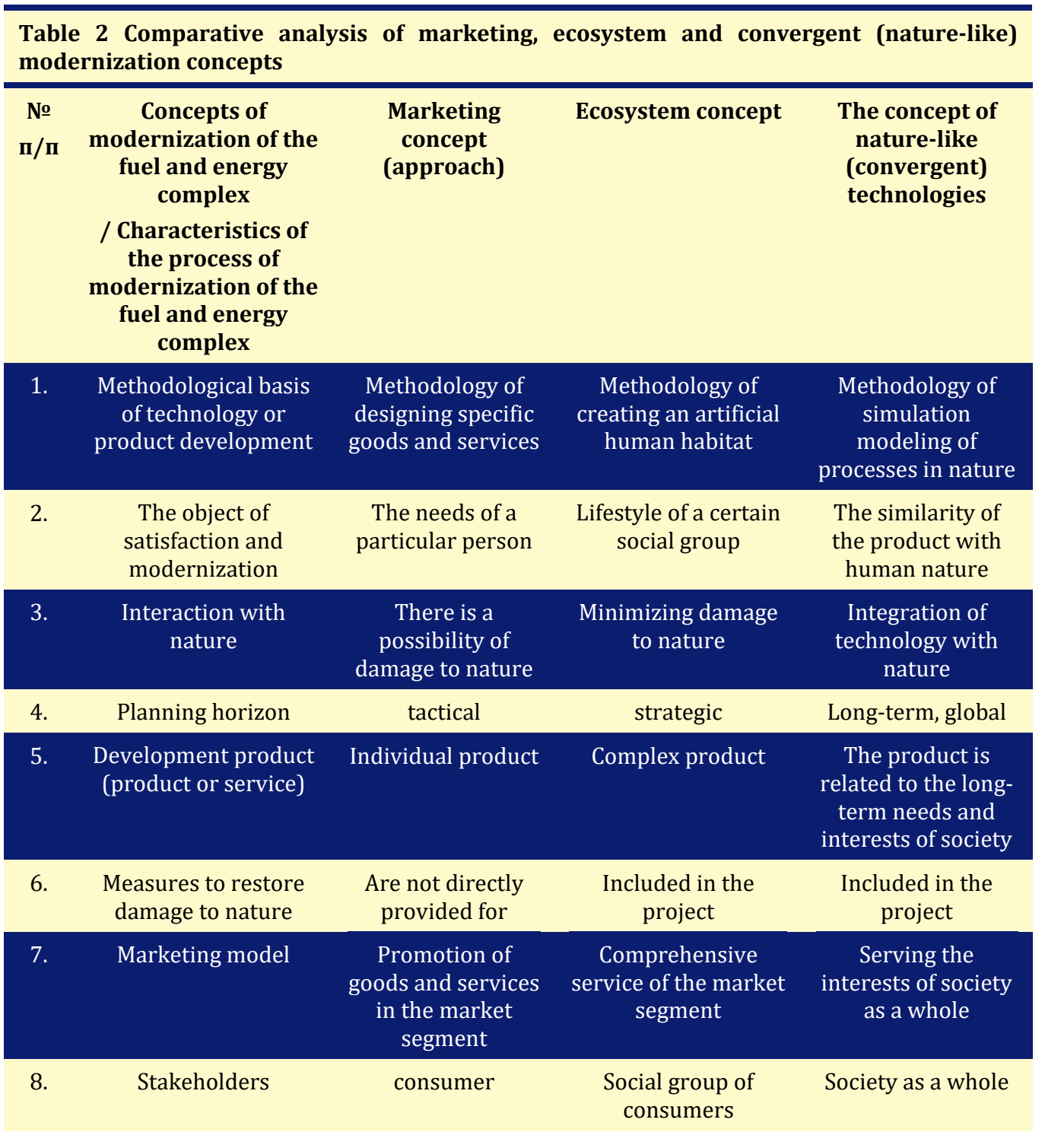




\begin{tabular}{ccccc} 
9. Competition factors & $\begin{array}{c}\text { Competence of the } \\
\text { staff }\end{array}$ & $\begin{array}{c}\text { Philosophy and } \\
\text { organizational } \\
\text { culture of the } \\
\text { company }\end{array}$ & $\begin{array}{c}\text { Organizational } \\
\text { culture of the } \\
\text { national innovation } \\
\text { system }\end{array}$ \\
\hline 10. & $\begin{array}{c}\text { Attitude to } \\
\text { competition }\end{array}$ & $\begin{array}{c}\text { The desire to win } \\
\text { the competition in } \\
\text { a certain market of } \\
\text { goods and services }\end{array}$ & $\begin{array}{c}\text { The desire to avoid } \\
\text { competition by } \\
\text { creating } \\
\text { comprehensive } \\
\text { pioneer products }\end{array}$ & $\begin{array}{c}\text { Competition at the } \\
\text { level of lifestyle and } \\
\text { culture of society }\end{array}$ \\
\hline 11. Efficiency criterion & Current profit & $\begin{array}{c}\text { The cost of the } \\
\text { company }\end{array}$ & $\begin{array}{c}\text { Proximity to } \\
\text { natural }\end{array}$ \\
12. & Market impact & $\begin{array}{c}\text { Impact on the } \\
\text { market segment }\end{array}$ & $\begin{array}{c}\text { Impact on the local } \\
\text { market }\end{array}$ & $\begin{array}{c}\text { Impact on the } \\
\text { global market }\end{array}$ \\
\hline
\end{tabular}

Source: developed by the author

\section{RESULT}

The materials of this article allow us to create an image of the future of the eighth technological order in the fuel and energy complex: modernization of machines based on new technologies; development of clusters, technological platforms, ecosystems; creation of new production institutes and implementation institutes; post-industrial method of innovation; development of ecosystem engineering and more.

The methodology of two-level modernization of technical infrastructure developed in this article creates the basis for the formation of a program for such modernization of the fuel and energy complex. This should be an ecosystem modernization of the technical infrastructure of the fuel and energy complex. The proposed method of modernization of technical infrastructure is post-industrial in nature. This means that the starting point of modernization is the development of new technologies of the eighth technological order. At the same time, the introduction of new technologies in the process of modernization ensures the economic efficiency of innovation activities in the development of the eighth technological order. Timely modernization of the technical infrastructure of the fuel and energy complex ensures the competitiveness and sustainability of the development of this complex. Multiple introduction (multiplication) of new technologies creates their economic efficiency. Therefore, when upgrading at the level of machinery and equipment, the main attention should be paid to the maximum use of new technologies to improve the safety and economic efficiency of these machines and equipment. When modernizing at the level of technological systems of the fuel and energy complex, special attention should be paid to the development of an ecosystem approach, the functioning of clusters and technological platforms, taking into account their institutional component.

The transition to an ecosystem approach will also require the modernization of existing institutions in the fuel and energy complex (systems of social and industrial relations between stakeholders). It may be necessary to create two types of new institutions: institutions focused on ensuring the creation of fundamentally new technologies of the fuel and energy complex; institutions aimed at introducing new technologies by integrating them with existing machines of previous technological orders Glushchenko (2021). These institutions should reflect the specifics of: the activities of companies; the eighth technological order; the ecosystem approach to the modernization of technical infrastructure. 


\section{CONCLUSION}

The article analyzes the development of a new technological order. The article substantiates that in order to ensure the sustainable development of the fuel and energy complex, it is necessary to modernize this complex. Such modernization should be based on an ecosystem approach. The methodology of two-level modernization of the technical infrastructure of the fuel and energy complex has been developed. At the first level of the technical infrastructure, machines are being upgraded using new technologies. The ecosystem approach should be implemented at the second level. The creation of this methodology opens up an opportunity for real modernization and development of the ecosystem approach in the fuel and energy complex. To do this, within the framework of a program-targeted approach to the modernization of the fuel and energy complex, it is necessary to develop a set of programs to modernize the existing technological infrastructure. The comparative analysis of the three concepts of modernization of the fuel and energy complex carried out in the article will make it possible to distinguish these concepts more clearly. This will accelerate the formation of concepts of ecosystem and nature-like modernization of the fuel and energy complex.

\section{REFERENCES}

A.A. Nikonova (2020). System synthesis in the development of mechanisms of innovative development of fuel and energy complex: methodological issues//Economic analysis: theory and practice. Vol. 19. No. 10 (505). pp. 1840-1869. Retrieved from https://doi.org/10.24891/ea.19.10.1840

A.E. Yakusheva, A.N. Sunteev (2020). The need for periodic renovation of equipment at industrial enterprises of the fuel and energy complex//In the collection: Economics, Management and Law in modern conditions. intercollegiate collection of articles. Togliatti, pp. 87-92.

Borovik G.G., Doroshenko K.V. (2020) The concept of an ecosystem, types of ecosystems and the main differences between natural and anthropogenic ecosystems//Student Forum. No. 30 (123). pp. 23-24.

Glushchenko V.V. (2020) Project model of functioning of the organizations// The scientific heritage, 2020, vol. 3, No. 53, p. 15- 33

Glushchenko V.V. (2021) The structure of the mechanism of development of social and professional institutions of the new technological order//Kazakhstan Science Journal. T. 4 . № 7 (32). C. 22-39. Retrieved from https://sciencejournal.press/sj/article/view/264/216

Kislitsyn E.V., Shishkov E.I. (2016) The main provisions of a systematic approach to the study of the fuel and energy complex//In the collection: . Materials of the International Scientific and Practical Conference. In 2 volumes. Responsible for the release of E.B. Dvoryadkin. Responsible editors: N.Y. Yaroshevich, N.V. Sbrodova, N.A. Istomina. pp. 18-22.

Kovalchuk M.V. (2021) Nature-like (convergent) technologies - global threats and challenges//SPbPU Science Weeks, Peter the Great St. Petersburg Polytechnic University, Retrieved from https://www.youtube.com/user/SPBMEDIA

L. K. Gurieva (2004) The concept of technological structures // Innovations : journal. - St. Petersburg, - No. 10. - pp. 70-75.

L.V. Ermolina, K.A. Ademasova (2020) The need for regular renovation of equipment at fuel and energy companies//In the collection: Current problems and 
trends in the development of the modern economy. Proceedings of the International Scientific and practical conference. In 2 parts. Editor-in-chief I.V. Kosyakova. Samara, pp. 9-14.

M. Mesarovich, D. Mako, I. Takahara (1973) Theory of hierarchical multilevel systems. - M.: Mir, pp.12-28.

S. Y. Glazyev and V. V. Kharitonov. - M.: Trovant, p.2 (2009) Nanotechnology as a key factor of the new technological order in the economy.

S.Yu. Glazyev (2016) World economic patterns in global economic development//Economics and mathematical methods. Vol. 52. No. 2. pp. 329. Retrieved from https://doi.org/10.2753/PET1061-1991520501

V. V. Glushchenko, (2021) Strategic planning of the transition of organizations to the sixth technological mode in the national economy// International Journal of Engineering Scientific Technologies, 5(1), 30 - 46.DOI: https://doi.org/10.29121/IJOEST.v5.i1.2021.159

V.V. Glushchenko (2020) The paradigm of intellectual management of the formation of the sixth technological order in the economy// The scientific heritage, vol. 4, No. 45, p. 54-63.

V.V. Karlusov, D.A. Yarkov (2020) Russian-Chinese cooperation in the oil industry as a driver of the development of the fuel and energy complex of Russia//Economy: yesterday, today, tomorrow. Vol. 10. No. 6-1. pp. 255266. 